\title{
S32205 Dubleks Paslanmaz Çeliğin TIG Kaynağında Soğuma Hızının Mikroyapısal Özelliklere Etkileri
}

\author{
Aziz Barış BAŞYİĞİT, Adem KURT \\ MKEK Mühimmat Fabrikası, Sanayi ve Teknoloji Müdürlüğü, Kırıkkale, 71451 Turkey. \\ Gazi Üniversitesi, Teknoloji Fakültesi, Metalurji ve Malzeme Mühendisliği Bölümü, Ankara Turkey \\ abbasyigit@gazi.edu.tr, ademkurt@gazi.edu.tr
}

\begin{abstract}
Welding of duplex stainless steels gains interest, significantly due to their increasing application fields. The problems come into question about the weldments of these steels improper distribution of important phases like delta-ferrite, austenite and other intermetallics. In order to maintain sufficient corrosion and mechanical properties in welding, the optimum delta-ferrite phase ratios must be kept within approximately $\% 35-65$ by volume.

In this study; thicknesses of $3 \mathrm{~mm} S 32205$ (2205) duplex stainless steel plates were TIG welded by pure argon shielding gas. The effects of various welding cooling circumstances on microstructural developments were examined.
\end{abstract}

Index Terms - Duplex Stainless Steels, TIG Welding, Cooling Rate Effects.

Özet- Dubleks paslanmaz çeliklerin kaynağı artan uygulama alanlarından dolayı belirgin şekilde ilgi kaynağı olmaktadır. Bu çeliklerin kaynaklı bağlantılarında oluşabilecek delta-ferrit, östenit ve diğer önemli metaller-arası fazların uygun olmayan dağılımları ile ilgili problemler önem kazanmaktadır. Kaynak işlemlerinde tatminkar korozyon ve mekanik özellikleri elde edebilmek için optimum delta ferrit oranları hacimce yaklaşık olarak \%35-60 aralığında olması gerekmektedir.

Bu çalışmada $3 \mathrm{~mm}$ kalınlığındaki 2205 dubleks paslanmaz çelik numuneler saf argon koruyucu gazı kullanılarak TIG kaynak yöntemi ile birleştirilmiştir. Farklı kaynak soğuma koşullarının mikroyapısal değişikliklere etkileri incelenmiştir.

Anahtar Kelimeler - Dubleks Paslanmaz Çelikler, TİG Kaynağı, Soğuma Hızı Etkileri.

\section{GIRIŞ}

$\mathrm{P}$ aslanmaz çelikler; martenzitik, ferritik, östenitik, dubleks (ferritik-östenitik), çökelti sertleştirilmiş (PH) şeklinde baskın olan metalurjik fazlara göre sınıflandırılmaktadır [1-4].

1980'li yıllardan beri hızla gelişen ve üstün korozyon direnci ile mukavemetin birarada istendiği; kimyasal, petro-kimyasal boru hatları, depolama tankları, kağıt endüstrileri, enerji santralleri, madencilik, gıda teknolojileri, köprüler gibi endüstrilerde dubleks paslanmaz çelikler artarak tercih edilmektedir [1,2]. Dubleks paslanmaz çelikler nispeten yüksek ferrit içeriklerinden dolayı manyetik özellik sergilerler $[1,2,3,4]$.

Dubleks paslanmaz çeliklerin kaynak edilebilirlikleri genel olarak iyidir. Ancak zararlı metallerarası bileşikler ile katılaşma ve hidrojen çatlağı oluşumu riskinden dolayı kaynak işleminde önlemler alınmalıdır [4].

Bununla birlikte; dubleks paslanmaz çeliklerin kaynak metalinde ve ITAB'da yer alan ferrit ve östenit dağılımları korozyon ve mekanik özelliklerini etkilemektedir. Kaynaklı bağlantı; gerilmeli korozyon çatlağına yeterli düzeyde dayanım için en az \%25, ana metalde sağlanan genel korozyon direnci ve tatminkar mekanik özelliklerin sağlanabilmesi için en fazla $\% 60 \delta$-ferrit faz içeriğine sahip olmalıdır [5].

Çalışmada; ER2209 kodlu ilave tel kullanılarak saf argon koruyucu gazı ile TIG kaynak yöntemiyle birleştirilen $3 \mathrm{~mm}$ kalınlıktaki S322205 (2205) dubleks paslanmaz çeliklerin kaynaklı bağlantısında değişen soğuma hızına göre oluşabilecek östenit, $\delta$-ferrit ve diğer muhtemel metaller-arası fazların miktarlarının mikroyapısal özelliklerle ilişkileri incelenmiş̧ir.

Bununla birlikte; soğuma hızının tane boyutuna etkisini görmek amaciyla ASTM E112 tane boyutu ölçümleri faz analizleri ile birlikte değerlendirilmiş, metalografik faz oranları tespitleri manyetik $\delta$-ferrit faz ölçümleri ile kıyaslanması imkanı da elde edilmiştir.

\section{DENEYSEL ÇALIŞMALAR}

Deneysel çalışmada $3 \mathrm{~mm}$ kalınlığındaki S32205 dubleks paslanmaz çelik plakalar TIG kaynağı yöntemi ile birleştirilmişlerdir.

2205 dubleks paslanmaz çelik ve kullanılan W22 93 NL, (ER 2209) TIG kaynak tellerinin kimyasal içerikleri Tablo 1' de verilmektedir.

TIG kaynak işleminde saf argon koruyucu gazı kullanılmıştır. TIG kaynağı uygulama koşulları Tablo 2' de verilmektedir. 
Tablo I.

2205 dubleks paslanmaz çelik ve W22 93 NL, (ER 2209) TIG kaynak tellerinin kimyasal içerikleri

\begin{tabular}{|l|c|c|c|c|c|c|c|c|c|c|c|}
\hline C & Mn & P & S & Si & Cr & Ni & Mo & Fe & N & Others \\
\hline 2205 dubleks paslanmaz çelik (ağırlıç̧a \%) \\
\hline 0,031 & 0,832 & 0,024 & 0,004 & 0,423 & 24,957 & 6,638 & 3,511 & 62,10 & 0,306 & 1,174 \\
\hline
\end{tabular}

Tablo II.

TIG kaynak parametreleri

\begin{tabular}{|c|c|c|c|c|c|c|c|c|c|c|c|}
\hline \multirow{2}{*}{$\begin{array}{l}\text { Altllk } \\
\text { Türü }\end{array}$} & \multirow{2}{*}{$\begin{array}{c}\text { Koruy } \\
\text { ucu } \\
\text { Gaz } \\
\text { Türü }\end{array}$} & \multirow{2}{*}{$\begin{array}{c}\mathrm{Gaz} \\
\text { Debisi } \\
\text { (litre/daki } \\
\mathrm{ka} \text { ) }\end{array}$} & \multirow{2}{*}{$\begin{array}{l}\text { Pasolar- } \\
\text { aras1 } \\
\text { Sicaklik } \\
\quad{ }^{\circ} \mathrm{C}\end{array}$} & \multirow{2}{*}{$\begin{array}{c}\text { Tungsten } \\
\text { Elektrot }\end{array}$} & \multicolumn{2}{|c|}{$\begin{array}{c}\text { Kaynak İlerleme } \\
\text { Hızı }(\mathrm{mm} / \mathrm{sn})\end{array}$} & \multicolumn{2}{|c|}{$\begin{array}{c}\text { Kaynak Akımı } \\
\text { DC (-) } \\
\text { (Amper) }\end{array}$} & \multicolumn{2}{|c|}{$\begin{array}{c}\text { Kaynak } \\
\text { Gerilimi } \\
\text { (Volt) }\end{array}$} & \multirow{2}{*}{$\begin{array}{c}\text { Is1 } \\
\text { girdisi } \\
\text { (ikinci } \\
\text { paso- } \\
\text { joule) }\end{array}$} \\
\hline & & & & & $\begin{array}{l}\text { Kök } \\
\text { Paso }\end{array}$ & $\begin{array}{l}\text { İkinci } \\
\text { Paso }\end{array}$ & $\begin{array}{l}\text { Kök } \\
\text { Paso }\end{array}$ & $\begin{array}{l}\text { İkinci } \\
\text { Paso }\end{array}$ & $\begin{array}{l}\text { Kök } \\
\text { Paso }\end{array}$ & $\begin{array}{l}\text { İkinci } \\
\text { Paso }\end{array}$ & \\
\hline $\begin{array}{l}\text { Seramik } \\
\text { Altlık }\end{array}$ & \multirow{3}{*}{$\begin{array}{c}\text { Saf } \\
\text { argon }\end{array}$} & \multirow{3}{*}{6} & \multirow{3}{*}{150} & \multirow{3}{*}{$\begin{array}{l}\text { \%2Th } \\
\text { içeren } \\
\text { tungsten } \\
\text { elektrot }\end{array}$} & 2,16 & 2,13 & \multirow{3}{*}{$75 \mathrm{~A}$} & \multirow{3}{*}{$100 \mathrm{~A}$} & \multirow[b]{2}{*}{$12 \mathrm{~V}$} & \multirow[b]{2}{*}{$13 \mathrm{~V}$} & \multirow[b]{2}{*}{427,23} \\
\hline $\begin{array}{c}\text { Seramik } \\
\text { Altlik }+ \text { S } \\
\text { u ile } \\
\text { Soğutma }\end{array}$ & & & & & 2,16 & 2,13 & & & & & \\
\hline $\begin{array}{l}\text { Bakır } \\
\text { Altlık }\end{array}$ & & & & & 1,88 & 2,04 & & & $11 \mathrm{~V}$ & $13 \mathrm{~V}$ & 446,08 \\
\hline
\end{tabular}

3 mm kalınlığındaki 2205 dubleks paslanmaz çelik sac malzemeler kaynak öncesi Şekil 1'de gösterilen ölçülerde kesilerek hazırlanmıştır.

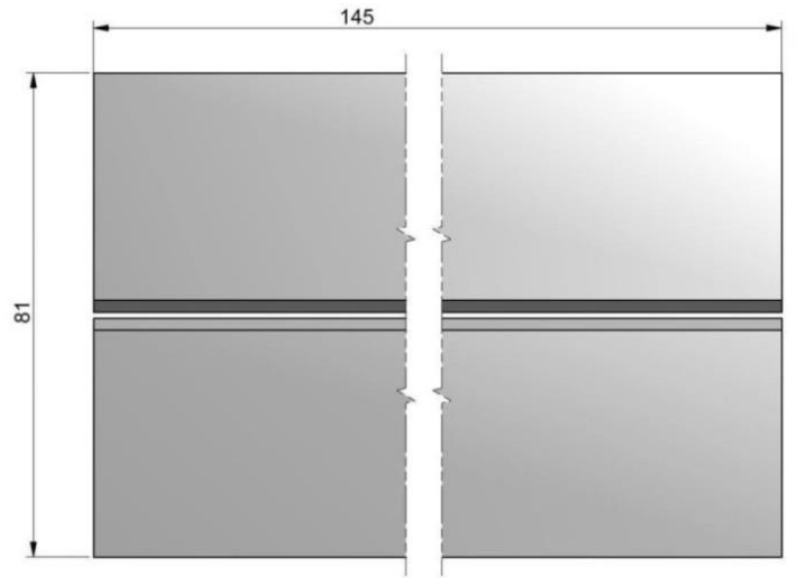

seramik altlıklar sırasıyla Șekil 2' de gösterilmektedir.

Şekil 1. Kaynak edilmek üzere hazırlanmış 2205 dubleks paslanmaz çelik numunelerin ölçüleri

A. Kaynak sonrası farklı soğuma hızları oluşturabilmek için kullanilan kaynak altlı malzemeleri ve özellikleri

Dubleks paslanmaz çelik kaynak metalinde farklı $\delta$-ferrit ve östenit faz dağılımı sağlamak için farklı soğuma şartları oluşturmak amacıyla isıl iletkenlik katsayılarındaki farklılıktan dolayı seramik ve bakır altlıklar kullanılmıştır.

Kaynak işleminde kullanılan, aynı form ölçülerine $(1,3 \mathrm{~mm}$ derinlik, $13 \mathrm{~mm}$ genişlik, $5 \mathrm{~mm}$ et kalınlığı) sahip olan bakır ve

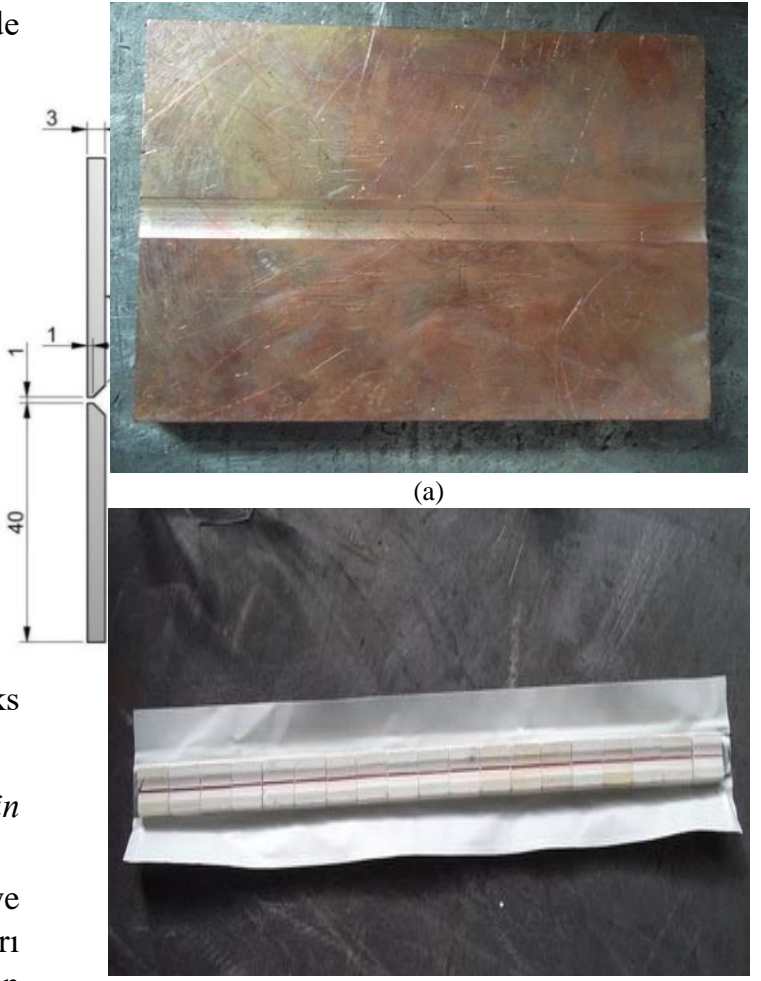

(b)

Şekil 2. (a) Saf elektrolitik bakırdan imal edilmiş ve (b) kendinden yapışkanlı seramik esaslı aynı profil ölçülerine sahip kaynak altlıkları 
Kaynak sonrası en yüksek soğuma hızı oluşturması hedeflenen bakır altlık ve en düşük soğuma hızı oluşturması hedeflenen seramik altlık 1sıl iletim özellikleri Tablo 3'de verilmiştir.

Tablo III.

Bakır ve seramik kaynak altlık malzemesi 1 sı iletim özellikleri $[6,7,8]$.

\begin{tabular}{|c|c|c|}
\hline $\begin{array}{l}\text { Kullanılan altlık } \\
\text { malzemesi }\end{array}$ & Bileşimi (ağırlıkça\%) & $\begin{array}{c}\text { Is1l iletkenlik } \\
\text { katsayıs } \\
\left(\mathrm{W} / \mathrm{m}^{\circ} \mathrm{K}\right)\end{array}$ \\
\hline $\begin{array}{c}\text { Elektrolitik saf } \\
\text { bakır }\end{array}$ & $\% 99,9 \mathrm{E}-\mathrm{Cu}$ & $372-374$ \\
\hline $\begin{array}{l}\text { Seramik altlık } \\
\text { (yarı-şamot tuğla } \\
\text { sinıfı) }\end{array}$ & $\begin{array}{c}\mathrm{SiO}_{2}: \% 61,80, \mathrm{Fe}_{2} \mathrm{O}_{3}: \% 0,63, \mathrm{Al}_{2} \mathrm{O}_{3}: \\
\% 24,03, \mathrm{CaO}: \% 0,68, \mathrm{MgO}: \% 1,17, \\
\mathrm{~K}_{2} \mathrm{O}: \% 2,38, \mathrm{Na}_{2} \mathrm{O}: \% 0,97 \text {, diğer: } \\
\% 6,99\end{array}$ & $0,96-1,40$ \\
\hline
\end{tabular}

Uygulanan TIG kaynağında seramik ve bakır altlıkların 1sıl iletkenlik değerlerinin arasındaki bu yüksek farklılık, kaynakta soğuma hızlarında değişime neden olmuştur. Kullanılan bakır ve seramik kaynak altlkkları 'Warmedurch Gang Heat Transition-Isı Transferi Yazılımı' vasıtasıyla ASTM C680 [9] standardı kapsamında simule edilerek kaynak koşullarının soğuma hızları arasındaki fark ortaya koyulmuştur.

Ayrıca kullanılan bu iki kaynak altlığına göre orta derecede soğuma hızı oluşturabilmek için diğer bir numune seramik altlık üzerinde kaynak edildikten sonra oda sıcaklığındaki $\left(22^{\circ} \mathrm{C}\right)$ suda soğutma işlemine tabi tutulmuştur.

\section{B. Kaynak Isl Girdisi Hesabı}

Kaynaklı birleştirmelerin 1Sı girdisinin hesaplanması için aşağıdaki net 1sı girdisi $\left(\mathrm{H}_{\text {net }}\right)$ eşitliğinden (Bkz. Eş 1.) yararlanılmıştır $[10,11]$.

$$
\mathrm{H}_{\text {net }}=(\eta \mathrm{xExI}) / \mathrm{V}
$$

Bu eşitlikte yer alan; $\eta$ : kaynak verimi, E: gerilim (Volt), I: Akım (Amper), V: kaynak ilerleme hızını (mm/sn) ifade etmektedir. Bu eşitliğe göre 1sı girdisi hesabında; TIG (DC-) kaynak yöntemi için $\eta: 0,70$, olmakta ve E: 13Volt, I:100A, $\mathrm{V}: 2,13 \mathrm{~mm} / \mathrm{sn}$; şeklinde TIG kaynağı sırasında kaynak makinesi ekranından tespit edilmiş olup, değerler net 1sı girdisi eşitliğinde yerine koyulursa;

Seramik altlık kullanılan birleştirmeler için, $\mathrm{H}_{\text {net }}=$ $0,7.13 .100 / 2.13, \quad \mathrm{H}_{\text {net }}=427,23$ joule $/ \mathrm{mm}$ ve bakır altlik kullanılan birleştirmeler için; $\mathrm{H}_{\text {net }}=0,7 \cdot 13 \cdot 100 / 2.04$, $\mathrm{H}_{\text {net }}=446,08$ joule $/ \mathrm{mm}$ şeklinde tespit edilmiştir.

\section{C.Ana Malzeme ve Kaynaklı Birleştirmelerin Mikroyapı} Incelemeleri

Çalışmada, ana malzeme ile birlikte farklı ferrit östenit oranlarında yapı oluşturacak şekilde kaynak edilen deney numunelerinin mikro yapılarının incelenmesinde optik metalurji mikroskobu cihazından yararlanılmıştır.

$\mathrm{Bu}$ incelemeler için hazırlanan tüm numuneler şeffaf bakalit kalıplama işlemine alındıktan sonra sırasıyla; 240, 320, 400, 600, 800, 1200 numaralı zımparalarla zımparalanmış ardından $3 \mu \mathrm{m}$ ve $1 \mu \mathrm{m}$ elmas pastalarla parlatma çuhasında parlatılmışlardır.

Farklı kaynak koşulları ile kaynak edilmiş olan kaynaklı numuneler; \%40 NaOH-saf su bileşimli çözeltide elektrolitik dağlama yöntemiyle dağlanmışlardır.

Ana malzeme; farklı dağlayıcı ile farklı kontrast oluşturarak fazların dağılımını tespit etmek amacıyla, \%10 oxalik asit-saf su bileşimli çözeltide elektrolitik olarak dağlanmıştır.

Optik mikroskop ile mikro yapısal incelemelerde 1000X büyütme kapasiteli Carl-Zeiss Jena marka metalurji mikroskobu kullanılmıştır. Numunelere, Kameram ve Metalim yazılımları vasıtasıyla; faz analizi uygulanmıştır. Optik metalografi incelemeleri ASTM A 923 [12] standardına göre $100 \mathrm{X}$ ve $500 \mathrm{X}$ büyütme oranlarında uygulanmıştır.

\section{Metalografik Yöntemle Fazların Miktarlarının}

\section{Belirlenmesi}

Ana malzemenin ve kaynaklı bağlantıların fazlarının belirlenmesi amaciyla ASTM E562 [13] ve ASTM E1245 [14] standarları kapsamında ve 'Kameram' faz analiz yazılımı yardımı ile 100x büyütme kapasitesinde metalografik faz analizi uygulanmıştır.

\section{E. Manyetik Yöntemle Fazların Miktarlarının} Belirlenmesi

Kaynaklı birleştirmelerden EN ISO 17655 [15] ve EN ISO 8249 [16] standartlarına göre manyetik yöntemle $\delta$-ferrit ölçümü için numunelerin kaynak üst ve alt yüzeylerindeki fazlalıklar taşlama ile giderilerek ölçüme hazır hale getirilmiştir. $\delta$-ferrit fazı miktarı manyetik ferrit ölçüm cihazı (Ferritetester SP 10-a) ile belirlenmiştir.

Manyetik $\delta$-ferrit fazı ölçüm işlemi, Şekil 3'de gösterildiği gibi EN ISO 17655 standardına göre birbirine $8 \mathrm{~mm}$. eşit mesafede kaynak merkez hattına konumlandırılmış 6 farklı noktadan ölçülmüş ve aritmetik ortalamaları alınarak $\delta$-ferrit fazı miktarları tespit edilmiş̧ir.

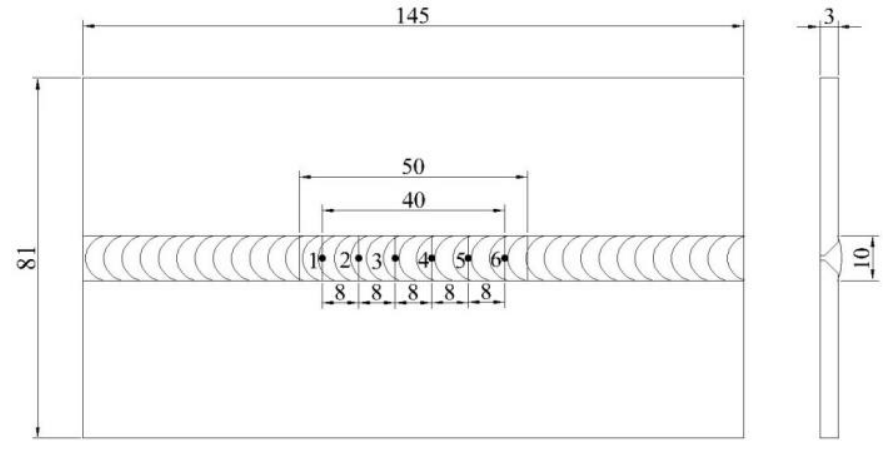

Şekil 3. EN ISO 17655 standardına göre kaynaklı numunelerden manyetik $\delta$ ferrit fazı ölçüm noktaları

Çalışmada yararlanılan manyetik yöntemle delta ferrit ölçümü yapan Ferritetester cihazı Şekil 4-(a) ve (b)'de gösterilmiştir. Ferritetester cihazı temaslı olarak çalışmakta olup her ölçüm sonucu anlık olarak hem FN (ferrit sayısı) hem de $\% \delta$-ferrit birimlerinden ekrana yansiyabilmektedir. 


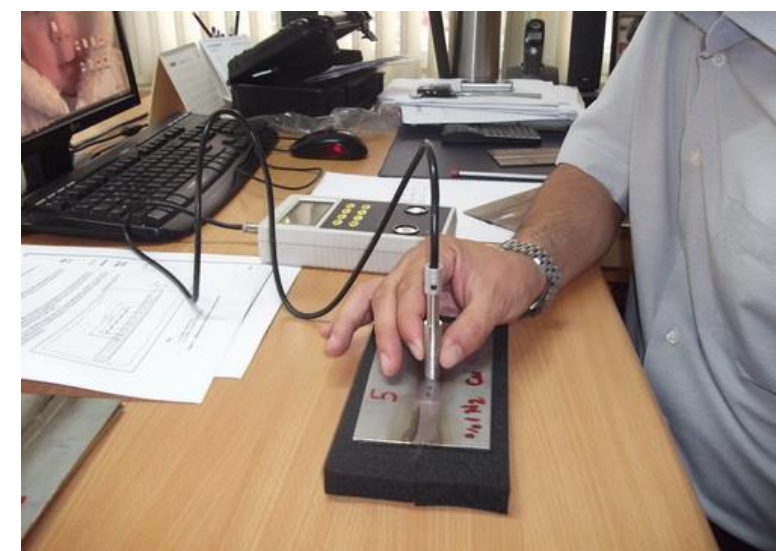

(a)

\section{FERRITE TESTER}

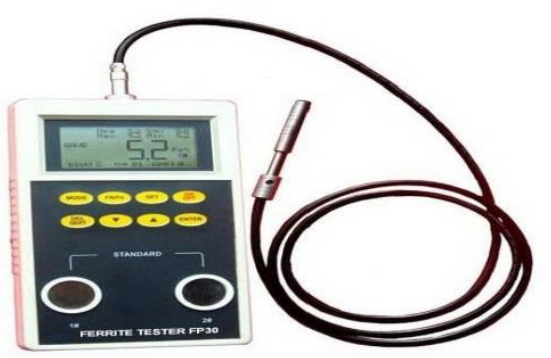

(b)

Şekil 4. Manyetik delta-ferrit ölçüm cihazının görünüşü (Ferritetester SP10.a) (a) Ölçüm yapılışı (b) Cihazın genel görünümü

Deneysel çalışmalar için temin edilen 2205 evsaflı dubleks paslanmaz çelik sacın manyetik ferrit öçüm cihazı sonuçları, ferritin manyetik yapıda bir faz olması yanında östenitin manyetik özellikte bir faz olmamasından faydalanılması prensibine dayanmaktadır. Kullanılan Ferritetester SP-10.a cihazı; ISO 8249 ve ANSI/AWS A4.2 standartları doğrultusunda kalibrasyon sertifikalarına sahiptir. Cihazın ayrıca iki farklı değere bağımsız laboratuarca onaylanmış iki kalibrasyon bloğu bulunmakta, ölçümlerin doğruluğu her an teyit edilebilmekte ve gerekirse tekrar kalibre edilebilmektedir. Cihazın ölçüm hassasiyeti \%30 Ferrit değerine kadar $\% \pm 2$ ve $\% 80$ Ferrit değerine kadar ise $\% \pm \% 3$ 'tür. Cihazın ölçüm belirsizliği $\% \pm 0.4$ (FN) şeklindedir. Cihaz \%0,1-\%80 ferrit (0,1-110FN) aralığında manyetik ferrit fazı ölçümü yapabilmektedir.

\section{DENEYSEL SONUÇLAR}

TIG kaynak yöntemi ile Tablo 2' de yer alan kaynak parametreleri doğrultusunda ve Şekil 1 'de gösterilen ölçülerde birleştirilen kaynaklı numuneler Şekil 5'de görülmektedir. Kaynak işlemi iki pasoda ve pasolar-arası sıcaklık maksimum $150^{\circ} \mathrm{C}$ olacak şekilde uygulanmıştır. Kaynaklı parçaların kenarları 25'er mm kesilip atılmış orta kısımdan mikroyapısal incelemeler için numuneler çıkarılmıştır.

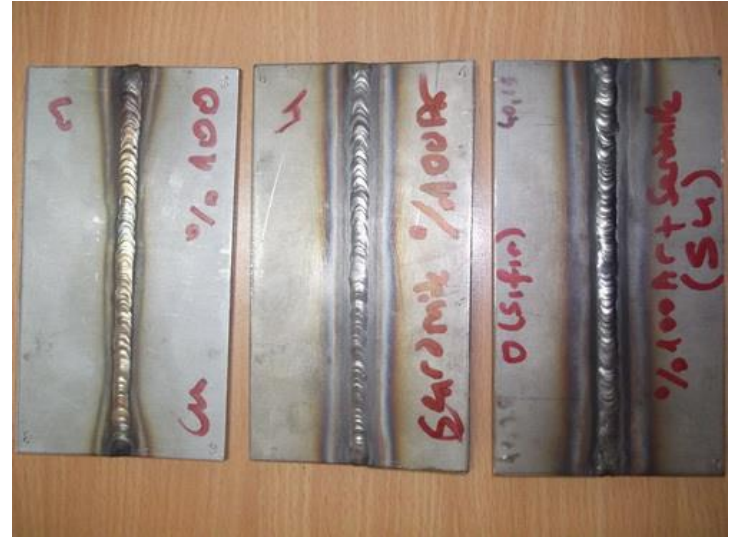

Şekil 5. Saf argon koruma gazıyla bakır, seramik ve seramik altlık kullanılarak birleştirme sonrası suda soğutularak elde edilen birleştirmeler

\section{A. Bakır ve Seramik Altlık Kullanımının Soğuma Hızına Etkileri}

Şekil 6-(a) ve (b)'den görüleceği üzere; 2205 dubleks paslanmaz çeliğe uygulanan kaynak işlemindeki koşullar 'Warmedurch Gang Heat Transition-Isı Transferi Yazılımı' yardımıyla bakır ve seramik altlık kullanımına göre, $1535^{\circ} \mathrm{C}$ olan kaynak metali ergime sınırı sıcaklığı $3 \mathrm{~mm}$ parça kalınlığı ve $5 \mathrm{~mm}$ bakır altlık kullanımı sonrasında dış cidarda $1442^{\circ} \mathrm{C}$ sıcaklığa anlık olarak ısı iletimi sağladığı tespit edilmiş, seramik altlıkta bu değer $990^{\circ} \mathrm{C}$ olarak belirlenmiştir.

$5 \mathrm{~mm}$ kalınlığındaki bakır altlık, kaynak ergime sınırı sıcaklığını $93^{\circ} \mathrm{C}$ düşürerek hızlı soğumaya neden olmuş, aynı kalınlıktaki seramik altlık ise bu sıcaklığ $1545^{\circ} \mathrm{C}$ düşürmüş yavaş soğumaya neden olarak ısı transferi gerçekleştirmiştir.
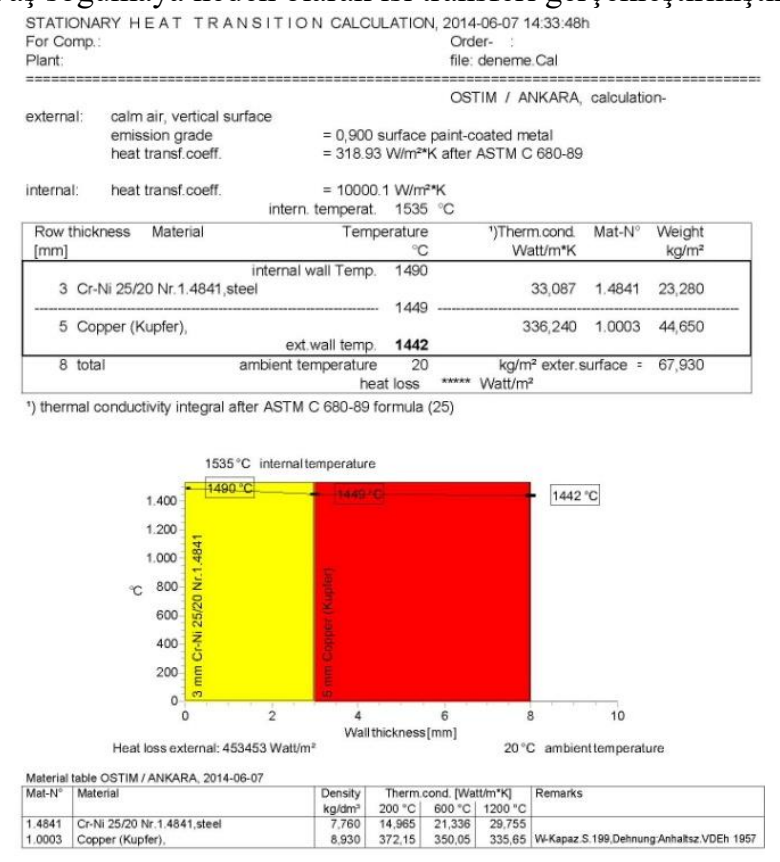

(a) 


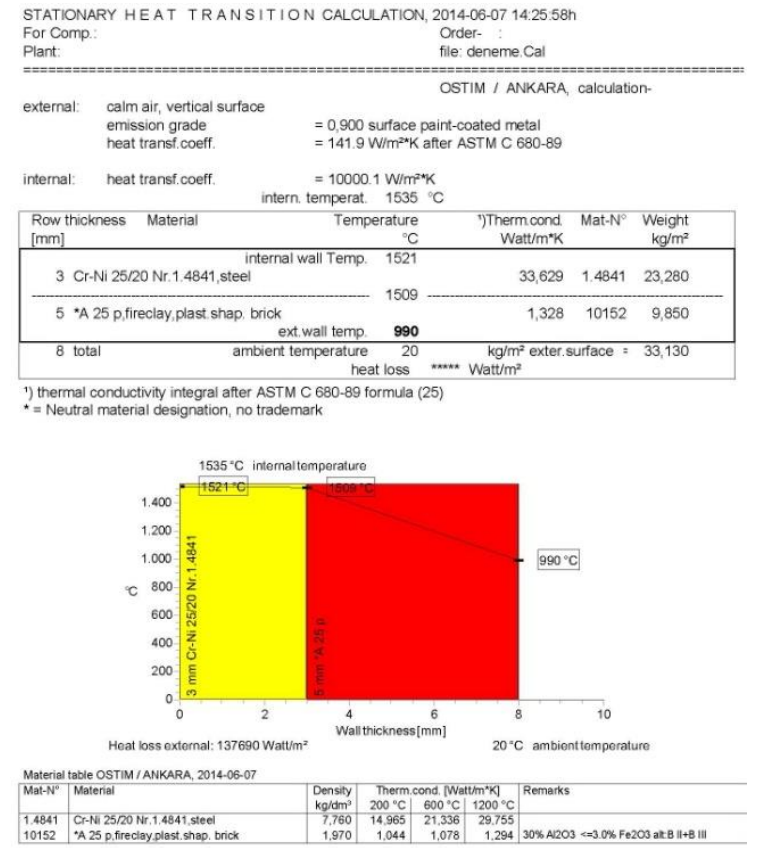

(b)

UNS S322205 (2205) dubleks paslanmaz çelik ana malzemenin kaynak öncesi mikroyapı görüntüleri incelenmiş, kaynak sonrası elde edilen mikroyapı görüntüleri ile karşılaştırmaları yapılmıştır. Dubleks paslanmaz çelik ana malzeme mikroyapı görüntüleri Şekil 8' de gösterilmiştir.

Şekil 8'de görülen açık renkli fazlar (beyaz) östeniti, koyu renkli (kahverengi) fazlar ise $\delta$-ferriti göstermektedir. Östenit ve $\delta$-ferritin hadde yönünde lameller şeklinde yönlendiği görülmektedir. Yapıdaki fazların ve hadde yönünün etkisinin daha net görülebilmesi için ana malzeme farklı büyütmelerde mikro yapısal olarak görüntülenmiştir. Şekil 8. (a) ve (b) sırasıyla $100 x$ ve $500 x$ büyütme ile hadde yönüne paralel yapıyı gösterirken, Şekil 8. (c) ve (d) sırasıyla 100x ve 500x büyütme ile hadde yönüne dik doğrultudaki yapıyı yansitmaktadır.

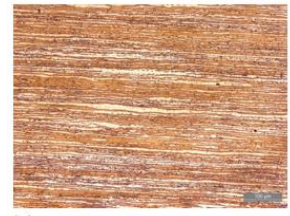

(a)

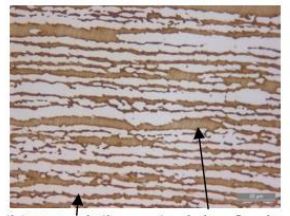

(b) östenit(beyaz) delta ferrit (c)

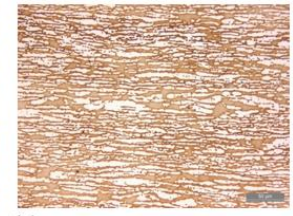

(c)

Şekil 6. Isı transfer analizi sonuçları (a) elektrolitik bakır altlık (b) seramik altlik

Bakırın 1sıyı seramiğe göre çok hızlı bir şekilde ve çok az 1sı transfer kayıplarıyla dış cidara taşıması yüksek ısıl iletkenlik yeteneği ve sonuç olarak yüksek kaynak bölgesi soğutma hızını açıklamaktadır.

\section{B. 2205 Dubleks Paslanmaz Çelik Ana Malzemenin Mikroyapisal Incelemesi}

Ana malzemenin mikroyapı incelemesi için hazırlanması işlemi Şekil 7 (a) ve (b)' de gösterilmiştir.

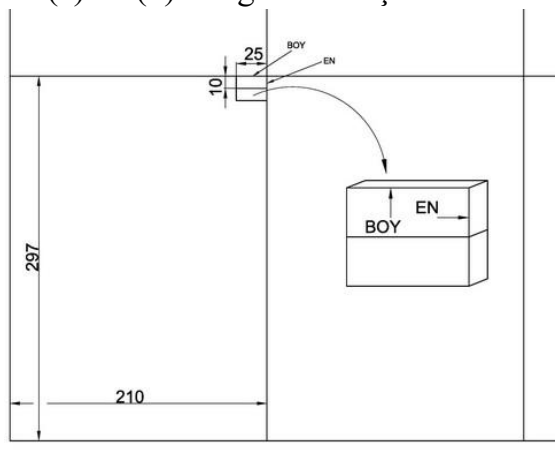

(a)

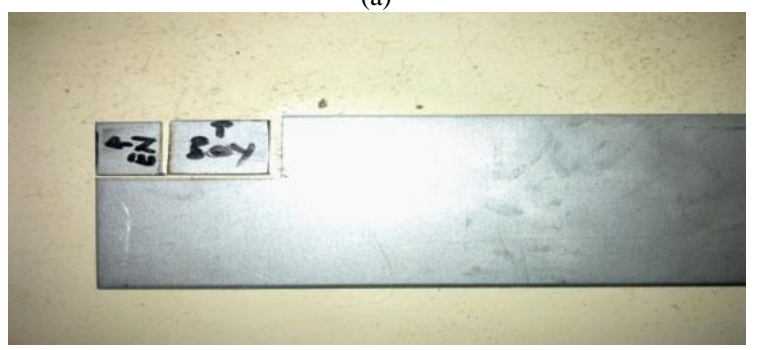

(b)

Şekil 7. 2205 dubleks paslanmaz çelik sacın temin edilmiş şekliyle mikroyapı incelemesi için hazırlanması (a) hadde yönü (b) numune kesimi

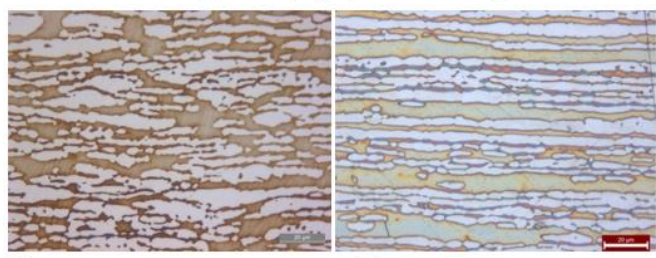

(d)

(e)

Şekil 8. Ana malzeme mikroyapı görüntüleri (a) hadde yönüne paralel, $\% 10$ oxalik asit (100x) (b) hadde yönüne paralel, \%10 oxalik asit (500x) (c) hadde yönüne dik, \%10 oxalik asit (200x) (d) hadde yönüne dik, \%10 oxalik asit (500x) (e) hadde yönüne paralel, $\% 40 \mathrm{NaOH}(500 x)$

\section{Kaynaklı Bağlantıların Mikroyapısal İncelemeleri}

Şekil 9' da bakır altlık kullanılan UNS S32205 dubleks paslanmaz çelik birleştirmesinin ITAB (Isının Tesiri Altındaki Bölge) ve kaynak metali mikroyapıları görülmektedir.

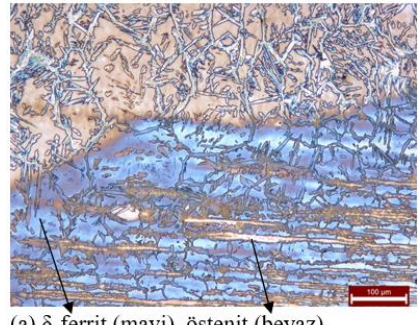
$\begin{array}{lcc}\text { (a) } \delta \text {-ferrit (mavi), östenit (beyaz), } & \text { (b) östenit (beyaz) } & \delta \text {-ferrit (kahverengi) } \\ \text { Şekil 9. Bakır altlık kullanılan kaynaklı birleștirmenin mikroyapı görüntüleri }\end{array}$ $(\% 40 \mathrm{NaOH})(\mathrm{a}) \mathrm{ITAB}(100 \mathrm{x})$ (b) kaynak metali (100x)

Şekil 9' da görüldüğü gibi, $\mathrm{NaOH}$ dağlayıcı kimyasalından dolayı; $\delta$-ferrit, kaynak metalinde kahverengi, ITAB'da ise mavi renkli olarak görülmektedir. Açık renkli (beyaz) yapılar ise östenittir. ITAB'a kadar hadde yönünü muhafaza eden ana malzeme yapısında ITAB'ın başlamasıyla $\delta$-ferrit taneleri toparlanmaya başlamakta ve geçiş bölgesine doğru iri taneli şekle dönüşmektedir. Geçiş bölgesinden itibaren sıvı kaynak metali, $\delta$-ferrit tanelerinden çekirdeklenerek katılaşmasını sürdürmektedir. Kaynak metalinde delta ferrit, tane sınırlarında 
östenitik levhalı yapı bir ağ tabakası şeklinde teşekkül etmiştir. Tane sınırlarından tane içlerine doğru dendrit kolları şeklinde östenitik yapıdaki kollar uzamıştır.

Çalışmada, seramik altlık kullanılarak birleştirildikten sonra suda soğutulan kaynaklı birleştirmenin mikroyapı görüntüleri Şekil 10'da gösterilmektedir.

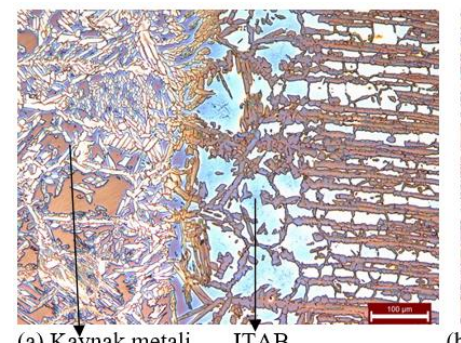

(a) Kaynak metali ITAB

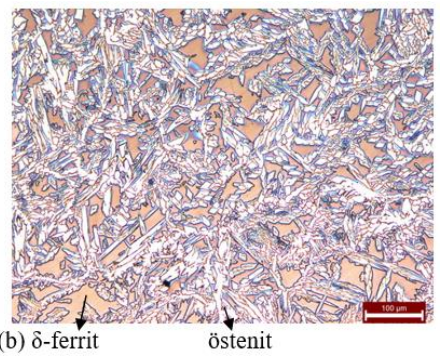

Şekil 10. Seramik altlık kullanılan ve suda soğutulan kaynaklı birleştirmenin mikroyapı görüntüleri $(\% 40 \mathrm{NaOH})(a)$ ITAB $(100 x)$ (b) kaynak metali (100x)

Seramik altlığın yanı sıra kaynak sonrası suda soğutma işlemi; sadece seramik altlık kullanılan numuneye göre daha yüksek ancak bakır altlık kullanılan numuneye göre yapıda daha düşük miktarda delta ferrit oluşumuna neden olmuştur. $\mathrm{Bu}$ duruma; seramik altlığın $1 \mathrm{~S} 1$ iletim katsayısının düşük olmasının kaynak sonrası soğuma hızını düşürerek delta ferritöstenit dönüşümü için daha fazla zaman imkanı tanımasının neden olduğu düşünülmektedir.

Son olarak; yalnızca seramik altlık kullanılan 2205 dubleks paslanmaz çelik birleştirmesinin mikroyapı görüntüsü ise Şekil 11 'de gösterilmiştir.

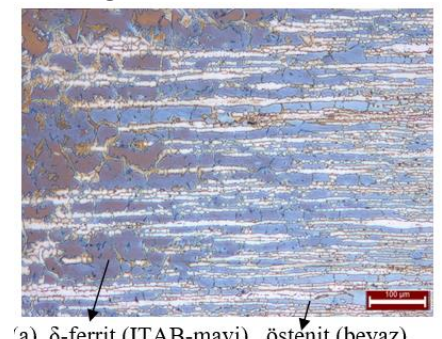

(a) $\delta$-ferrit (ITAB-mavi) östenit (beyaz)

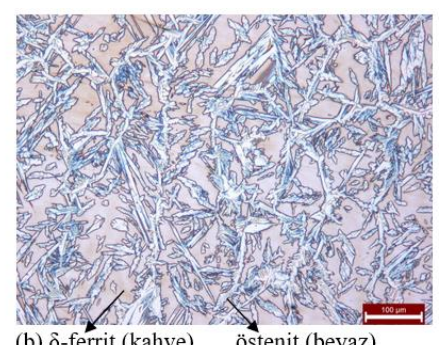

(b) $\delta$-ferrit (kahve) östenit (beyaz)

Şekil 11. Seramik altlık kullanılan kaynaklı birleştirmenin mikroyapı görüntüleri (a) ITAB (100x) (b) kaynak metali (100x)

Şekil 11' de görüldüğü gibi, seramik altlık kullanılarak en yavaş soğuyan deney numunesinde ferrit-östenit dengesinin östenit miktarı lehine artı̧̧ eğilimi gösterdiği göze çarpmaktadır.

D.Ana malzemenin ve Kaynaklı Bağlantıların Mikroyapısal Yöntemlerle Faz Miktarlarının Tespit Edilmesi

ASTM E-562, ASTM E 1245 standartları doğrultusunda Görüntü (faz) analizleri kullanılarak fazların miktarsal dağılımları hesaplanmıştır. Şekil 12' de ana malzeme ile birlikte seramik altlık kullanılarak birleştirilmiş ve kaynak sonrası suda soğutulmuş kaynaklı numunelerin faz dağılımları görülmektedir.

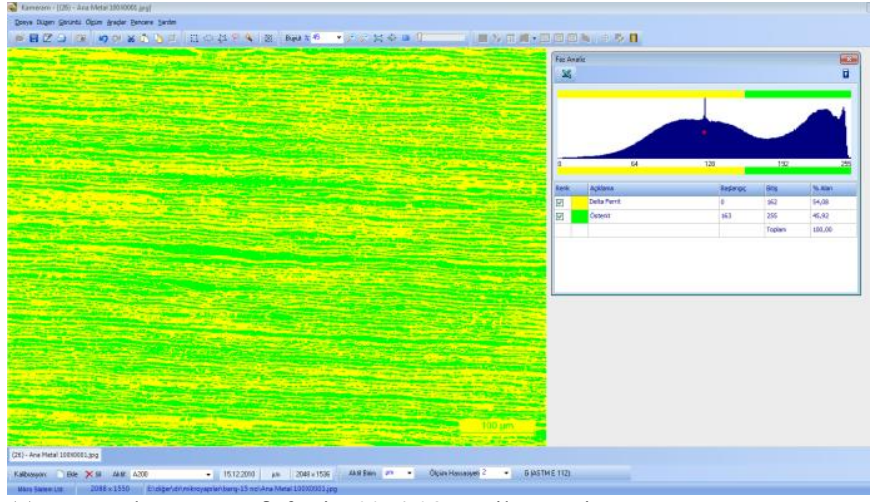

(a) Ana malzeme sarı: $\delta$-ferrite $\% 54,08$, yeşil: östenit $\% 45,92$

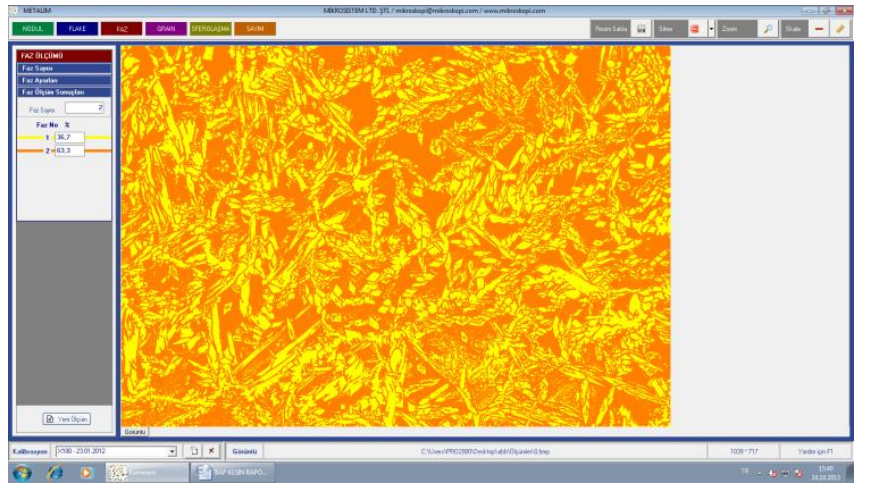

(b) Seramik altık kullanılan suda soğutulan kaynaklı numune, turuncu: $\delta$ ferrit $\% 63,3$, sar1: östenit $\% 36,7$

Şekil 12. (a) Ana malzemenin ve (b) seramik altlık kullanılan kaynaklı numunenin faz analizi sonucu

Ana malzeme ve kaynaklı numunelerin faz (görüntü) analiz sonuçları Tablo 4' de görülmektedir. Kaynak işlemi uygulanmamış ana malzemenin $\delta$-ferrit içeriği yaklaşık \% 54 iken, seramik altlık kullanılan kaynaklı numunede \%58 bulunmuştur. Seramik altlık kullanılan ve suda soğutulan kaynaklı numunede bu oran \%63,3 iken en hızlı soğuma gücünü sergilemiş olan bakır altlıklı numunede $\% 71,90$ delta ferrit tespit edilmiştir.

Tablo 4' den de görüleceği üzere artan kaynak soğuma hızı delta-ferrit içeriğini artırmaktadır.

Tablo IV.

Ana malzeme ve kaynaklı numunelerin faz analiz sonuçları

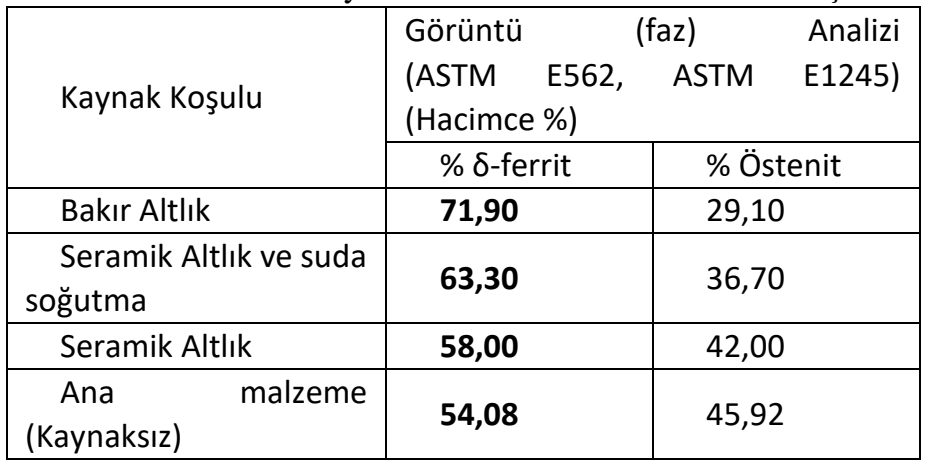


Tablo V.

$\delta$-ferrit fazının manyetik ölçüm sonuçları

\begin{tabular}{|c|c|c|c|c|c|c|c|}
\hline \multirow{2}{*}{$\begin{array}{c}\text { Kaynak altlıkları } \\
\text { (soğuma koşulları) }\end{array}$} & \multicolumn{6}{|c|}{ (Ferritetester- ISO 8249 ve ANSI/AWS A4.2- cihazı kullanılarak) EN ISO 17655 Standardına göre Bağımsız 6 Farklı } \\
\cline { 2 - 8 } & $1.0 ̈ l c ̧ u ̈ m$ & $2.0 ̈ l c ̧ u ̈ m$ & 3. Ölçüm & 4. Ölçüm & 5. Ölçüm & $6.0 ̈$ Oçüm & $\begin{array}{c}\text { Aritmetik } \\
\text { Ortalama }\end{array}$ \\
\hline Bakır & 73,8 & 72,3 & 77,6 & 67,6 & 68,0 & 67,4 & $\mathbf{7 1}$ \\
\hline Seramik+Suda Soğutma & 61,6 & 61,9 & 64,0 & 61,3 & 62,3 & 61,9 & $\mathbf{6 2}$ \\
\hline Seramik & 59,5 & 59,1 & 61,2 & 61,6 & 59,4 & 59,6 & $\mathbf{6 0}$ \\
\hline Ana malzeme & 53,8 & 53,6 & 55,5 & 55,9 & 56,1 & 56,7 & $\mathbf{5 5}$ \\
\hline
\end{tabular}

Seramik altlık kullanımından bakır altlı̆̆a doğru soğuma hızı arttıkça delta-ferrit oranı artmakta östenit oranı azalmaktadır. Kaynak sırasında ergime sıcaklı̆̆ını geçen kaynak metali sıvı faz yapısından soğuma üzerine yüksek sıcaklık $\delta$-ferriti ilk olarak katılaşacak ve artan soğuma hızı ile orantılı olarak yapıda bulunacaktır. Azalan soğuma hızı ile östenitin $\delta$-ferritten çekirdeklenmesine firsat olacak ve o oranda östenit içeriği artacaktır.

E.Ana Malzemenin ve Kaynaklı Bağlantıların Faz Miktarlarının Manyetik Yöntemlerle Tespit Edilmesi

Faz oranlarını belirlemek için uygulanan faz analizi yazılımının sonuçlarıyla karşılaştırma yapmak amacıyla $\delta$-ferrit fazının manyetik özellikte olması östenit fazının ise paramanyetik özellikte olmasından yararlanılarak, ISO 8249 ve EN ISO 17655 standartlarına göre Şekil 3' de gösterilen koşullarda manyetik faz ölçümleri uygulanmıştır.

Manyetik $\delta$-ferrit fazının ölçüm sonuçları Tablo 5' de gösterilmektedir. Ölçüm sonuçları, faz (görüntü) analizi sonuçlarına benzerlik göstermekte ve bu durum faz analizi sonuçları ile manyetik ölçüm sonuçlarının tutarlılığını ortaya koymaktadir.

$\delta$-ferrit fazının manyetik ölçüm sonuçları ile birlikte görüntü (faz) analizleri kıyaslaması grafiği Şekil 13' de verilmektedir

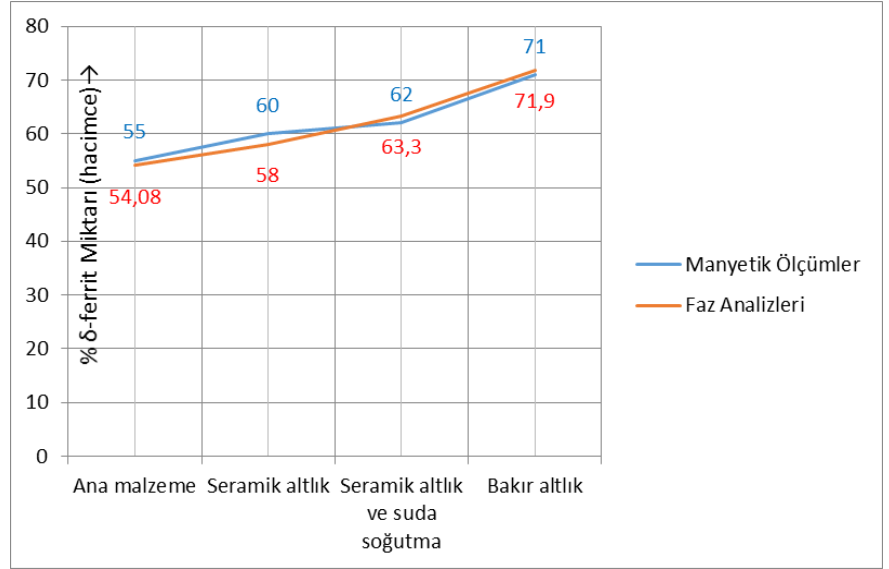

Şekil 13. Manyetik ölçümler ile faz analizlerinin kıyaslanması

Şekil 13' de manyetik ölçümler ile faz (görüntü) analizleri sonuçlarının birbirine yakın olduğu görülmekte, manyetik ölçüm yönteminin pratik ve hızlı oluşu faz (görüntü) analizi için numunelerin hazırlanma zorluğunu ortadan kaldırmaktadır. Ancak manyetik faz ölçüm yönteminde ise sadece manyetik karakterde olan fazların ölçümü yapılabileceğinden yöntemin sınırı olarak karşımıza çıkmaktadır. Bunun yanında, sahada boru hatları v.b. imalat esnasında manyetik ölçüm yöntemi $\delta$-ferrit içeriğinin korozyon ve mekanik dayanımı sağlayabilmek için arzu edilen içerikte olduğunu pratik ve hızlı bir şekilde ölçme imkanı sağlamaktadır.

\section{F. Ana Malzeme ve Kaynaklı Bağlantıların Tane Boyutlarının Incelenmesi}

Çalışmada, faz (görüntü) analiz programının tane boyutu modülü kullanılarak (kaynaksız) ana malzeme ile birlikte kaynaklı birleştirmelerin kaynak metali östenit ve delta ferrit fazlarının ASTM E 112 standardı kapsamında tane boyutları hesaplanmış, bulgular Tablo 6'da verilmektedir.

Tablo VI.

Ana malzeme ve kaynaklı numunelerin ASTM tane boyut ölçümleri

\begin{tabular}{|c|c|c|c|c|}
\hline \multirow{2}{*}{$\begin{array}{c}\text { Kaynak } \\
\text { Altlığ } \\
\text { (soğuma } \\
\text { koşulu) }\end{array}$} & \multicolumn{2}{|c|}{ Östenit } & \multicolumn{2}{c|}{ Delta Ferrit } \\
\cline { 2 - 5 } & $\mu \mathrm{m}$ & $\begin{array}{c}\text { ASTM No. } \\
\text { (ASTM E } \\
112)\end{array}$ & $\mu \mathrm{m}$ & $\begin{array}{c}\text { ASTM No. } \\
\text { (ASTM E } \\
112)\end{array}$ \\
\hline $\begin{array}{c}\text { Ana malzeme } \\
(\text { A) }\end{array}$ & 8,14 & 10,5 & 7,94 & 10,5 \\
\hline Bakır & 7,02 & 11,0 & 21,36 & 8,0 \\
\hline Seramik+su & 8,15 & 10,5 & 21.67 & 8,0 \\
\hline Seramik & 9,77 & 10,0 & 28.54 & 7,0 \\
\hline
\end{tabular}

Tablo 6'dan görüleceği gibi, kaynaklı numunelerde delta ferritin tane boyutu östenitin tane boyutundan büyüktür. Bir başka ifadeyle östenit delta ferrite göre ince taneli bir yapıya sahiptir.

Ana malzemenin östenit ve delta ferrit tane boyutları sırasıyla ASTM E 112'ye göre $10,5(8,14 \mu \mathrm{m})$ ve 10,5 $(7,94 \mu \mathrm{m})$ olarak tespit edilmiş, bu denge tane boyutu değeri

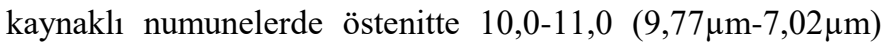
aralığında, delta ferritte ise 7,0-8,0 (28,54-21,36 $\mu \mathrm{m})$ aralığında görülmüştür.

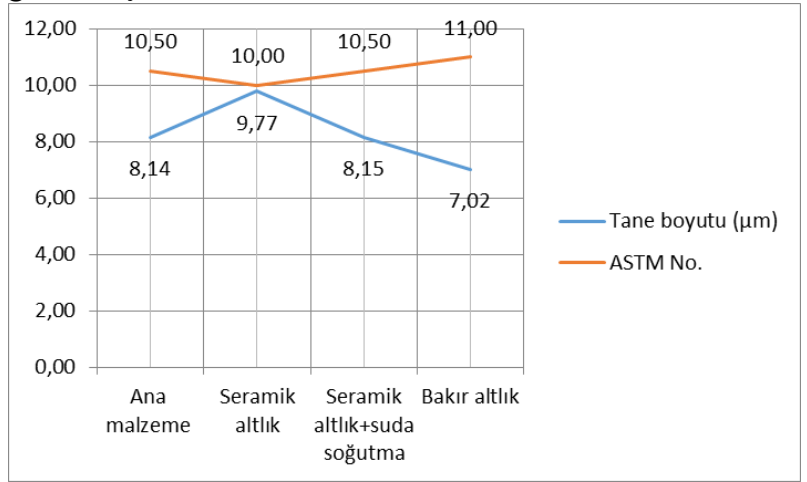

Şekil 14. Östenitin soğuma hızına göre tane boyut değişimi (ASTM E112) 
Şekil 14 ve Şekil $15^{\prime}$ de sırasıyla östenit ve delta ferritin soğuma hızlarına göre tane boyutlarının değiş̧imi grafiklerde gösterilmektedir. Kaynaklı numunelerde altlık kullanımına göre soğuma hızı arttıkça östenit ve delta ferritin tane boyutunun inceldiği görülmektedir.

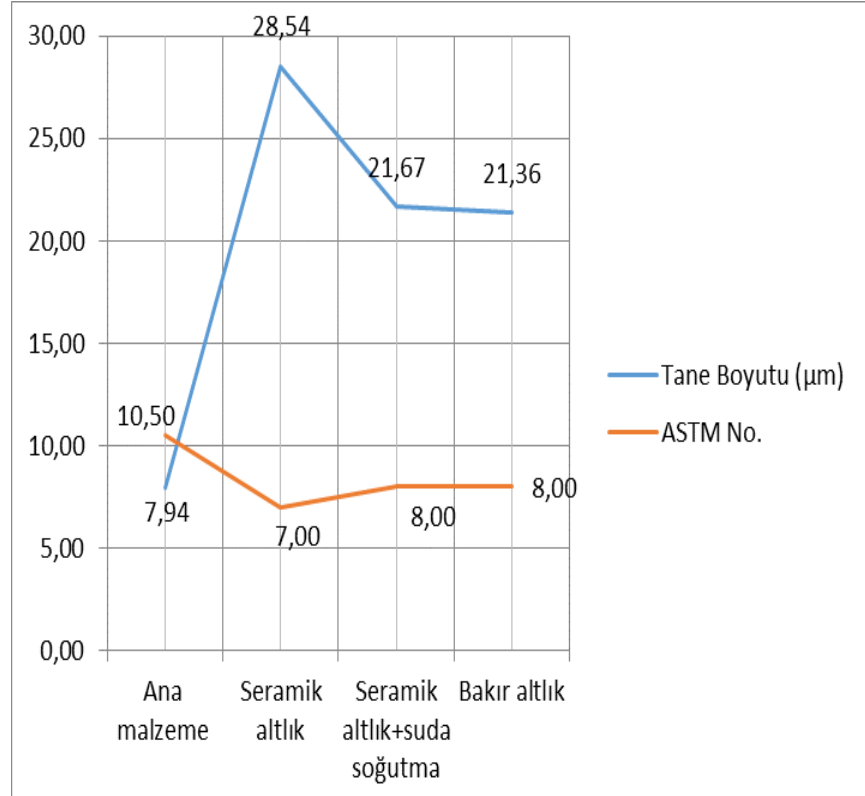

Şekil 15. Delta-ferritin soğuma hızına göre tane boyut değişimi (ASTM E112)

\section{SONUÇLAR VE TARTIŞMA}

Şekil 8'de gösterilen ana malzeme mikro yap1 görüntüleri bir arada değerlendirildiğinde; ana malzeme, \%55-\%45 $\delta$ ferrit-östenit faz oranlarından meydana gelen ferritik matriks içerisinde östenit tanelerinden oluşmaktadır. Ana malzeme yapısında ferrit fazı klor içeren korozif bir ortamda östenite göre daha fazla etkilendiği için elektrolitik olarak dağlanan bu numunelerde $\delta$-ferrit kahverengi, östenit fazı ise beyaz renkli görülmektedir.

Dubleks paslanmaz çelikler optimum mekanik ve korozyon özelliklerini bir arada sergileyebilmeleri için oda sıcaklığı mikro yapıları yaklaşık olarak yarı yarıya ferrit-östenit faz dağılımında olması gerekmektedir. Bu faz dağılımını elde etmek amaciyla; 2205 dubleks paslanmaz çelikler, üretim aşamalarında son işlem olarak $1050-1060^{\circ} \mathrm{C}$ sicaklıkta çözeltiye alma 1sıl işlemine tabi tutulduktan sonra hızla oda sıcaklığına suda soğutulmaktadırlar. Kimyasal bileşimlerine ve soğuma hızına bağlı olarak dubleks paslanmaz çeliklerde yapı yaklaşık olarak yarı yarıya ferrit-östenit içeriğinde meydana gelmekte ve artan soğuma hızı delta-ferrit oranını artırmaktadır[1,2]. Bu sebeple, çalışmada kullanılan deney malzemelerinin ana malzeme ferrit-ostenit dengesi kaynak termal koşullarından etkilenerek, 1sı iletiminin yüksek olduğu bakır altlık kullanılarak elde edilen yüksek soğuma hızı ferrit içeriğini en yüksek orana çıkarırken, en düşük 1sı iletiminin olduğu seramik altlık kullanılan numunede ise yavaş soğumadan dolayı östenit içeriği artmış ve kaynak bölgesinden daha geç transfer edilebilen kaynak 1s1 enerjisinden dolayı ferrit tanelerinin daha fazla kabalaştı̆ı tane boyut analizinden görülmektedir. Artan soğuma hızı hem östenitin hem de deltaferritin tane boyutunu inceltmektedir. Bununla birlikte; kaynaklı numunelerde östenitin tane boyutu delta ferritten daha ince tespit edilmiştir.

Birleştirmelerin 1s1 tesiri altındaki bölgelerinin mikro yapısında ise kaynak sonrası en yüksek soğuma hızının etkisi görülürken kaynak termal çevrimine bağlı olarak ITAB ferrit östenit dengesi bu bölgede ulaşılan sıcaklığa bağlı olarak ferrit lehine değişim gösterirken aynı zamanda sıcaklığın yükselmesine bağlı olarak ferrit tanelerinin kabalaştı̆̆ yine net olarak görülmektedir. Bakır altlık kullanılan numunenin ITAB genişliği, seramik altık kullanılan numuneye oranla yüksek soğuma hızından dolayı daha dar tespit edilmiştir.

Dubleks paslanmaz çelikler için kullanılan denge diyagramları göz önünde bulundurulduğunda, kaynak metalinin ITAB bölgesinde ulaşılan sıcaklıklar metalin ergime katılaşma sıcaklığına kadar ulaştığından yapıdaki ferritin ulaşılan sıcaklığa ve bu sıcaklıkta bekleme süresine bağlı olarak kabalaşması kaçınılmaz olmaktadır. Soğuma sürecinde ise bu fazın dönüşümü için yeterli zaman bulunmadığından yapıda kaba olarak kalmaktadır. Dubleks paslanmaz çeliklerin bilhassa ITAB ferrit tanelerinde $\mathrm{Cr}_{2} \mathrm{~N}$ gibi ikincil faz metallerarası bileşiklerin oluşması ulaşılan sicaklığa ve bu sicaklıkta bekleme süresine göre değişmektedir. Bu oluşan metallerarası bileşiklerin olduğu bölgeler dağlama sırasında çözeltiden etkilenerek hassaslaşmış bir bölge olarak görülebilmektedir [1,2]. Ancak bu çalışmada bu tür hassaslaşmış bölgelere rastlanmamıştır.

Farklı soğuma rejimlerine maruz kalan deney numunelerinin kaynak metali mikroyapı incelemelerinde göze çarpan en belirgin husus ana metal mikro yapısının tamamen kaynak termal çevriminden ve kaynak ilave metalinden etkilenerek sıvı kaynak banyosunun katılaşma sürecinde ITAB kaba tanelerinden başlayarak kaynak merkezine doğru kolonsal taneler şeklinde katılaşarak, katılaşma sonrasında oda sıcaklığına doğru soğuma sürecinde matrisi oluşturan kolonsal ferrit tane sınırlarından oluşan levhalı widmanstatten ve tane içinde oluşan östenit tanelerinden meydana geldiği görülmektedir.

Ancak kaynak metali mikro yapısında görülen diğer önemli husus, ana metaldeki yaklaşık eşit ferrit-östenit dengesi kaynak sonrası soğuma hızına bağlı olarak değişmesidir. Yüksek soğuma oranının elde edildiği bakır altlık kullanılan numunede ferrit miktarındaki artış eğilimi fazla iken, seramik altlık kullanılarak yavaş soğuyan deney numunesinde ferrit östenit dengesinin östenit miktarı lehine artış eğilimi gösterdiği göze çarpmaktadır.

Ana malzemenin mikroyapıları ile dubleks kaynak metali final mikroyapısının oluşumunda 1sı girdisi, kimyasal bileşim ve soğuma hızının kontrolü en etkili parametreler olduğu için deney numunelerinde ortaya çıkan farklı ferrit-östenit faz oranlarının, tatminkar korozyon ve mekanik dayanımları sağlayabilecek ana malzemedeki ilk faz oranlarını elde edebilmek için soğuma hızının seramik altık kullanımında 
olduğu gibi kontrol edilmesi bu çeliklerin kaynaklı bağlantılarında yarar sağlayacaktır. Bununla birlikte; çalışmada elde edilen mikroyapıların literatürde ifade edilen örneklerle uyum halinde olduğu düşünülmektedir $[1,2,17,18,19,20]$.

\section{REFERENCES}

[1] J. Lippold and D. Kotecki: Welding Metallurgy and Weldability of Stainless Steels, Wiley Interscience Publications, New Jersey (2005)

[2] Gunn N. Robert: Duplex Stainless Steels, Microstructures, Properties and Applications, Abington Publishing, Cambridge, England (2003)

[3] Pierre R. Roberge, Handbook of corrosion engineering, Materials Selection, Chapter 8, McGrawhill Publications, (2000)

[4] David N.Noble, Microstructural Development, Duplex Stainless Steels, ASM Handbook Volume 6. Welding Brazing and Soldering ASM International, USA, p.1218, (1993).

[5] ASM Handbook Volume 13-B. Corrosion. Corrosion of Duplex stainless steel weldments, ASM International, p.813, (1992)

[6] Topbaş M. A. Endüstri Fırınları. Cilt I. Kurtiş Yayıncılık. İstanbul, (1991), 157.

[7] Bayazıtoğlu Y. Özışık M. N. (1988). Elements of Heat Transfer. McGraw-Hill Book Company, USA, 419.

[8] E. Dwight: American Institute of Physics Handbook 3rd Edition, McGraw Hill Pubs, (1972)

[9] ASTM C680, Standard Practice for Estimate of the Heat Gain or Loss and the Surface Temperatures of Insulated Flat, Cylindrical, and Spherical Systems by Use of Computer Programs (2014),

[10] Chon L. Tsai Chin M. Heat flow in Welding. Ohio State University. ASM Handbook Volume 6. Welding Brazing and Soldering ASM International, USA, 7-17, (1993).

[11] Weisman C. AWS Welding Handbook. 7th Edition. Heat flow in welding, 81, (1981).

[12] ASTM A 923-08 'Standart Test Methods for Detecting Detrimental Intermetallic Phase in Duplex Stainless Steels, USA, (2008)

[13] ASTM E-562-11, Standard Test Method for Determining Volume Fraction by Systematic Manual Point Count, (2011)

[14] ASTM E 1245-03, Standard Practice for determining the Inclusion or Second Phase Constituent Content of Metals by Automatic Image Analysis (Re-approved 2008)

[15] EN ISO 17655. (2003). Destructive tests on welds in metallic materials-method for taking samples for delta ferrite measurement. European Standard, Brussels.

[16] EN ISO 8249. (2000). Welding-determination of ferrite number (FN) in austenitic and duplex ferritic-austenitic $\mathrm{Cr}-\mathrm{Ni}$ stainless steel weld metals, European standard, Brussels.

[17] Metallography and Microstructures of Stainless Steels and Maraging Steels, ASM Handbook Vol.9 ASM International, (2004)

[18] Zhang W. Debroy T. Palmer T. A. Elmer J. W. Modeling of ferrite formation in a duplex stainless steel weld considering non-uniform starting microstructure, USA, Actamaterialia Journals. (2005).

[19] Santos T. F. A. Marmho R. R. Paes M. T. P. Ramirez A. J. Microstructure evaluation of UNS S 32205 duplex stainless steel friction stir welds, Brazil.

[20] Palmer T. A. Elmer J. W. Babu S. S. (2004). Observations of ferrite/austenite transformations in the heat affected zone of 2205 duplex stainless steel spot welds using time resolved X-ray diffraction, Materials Science and Engineering. 